\title{
Barriers to cervical cancer screening exist despite integrating HIV and gynaecological services for HIV-positive women in Poland
}

\author{
Justyna Dominika Kowalska1, 2, Agnieszka Wroblewska', ${ }^{1}$, Piotr Ząbek1, Ewa Firląg-Burkacka1, \\ Monika Kalinowska ${ }^{1}$, Zofia Byczot ${ }^{1}$, Andrzej Horban ${ }^{1,2}$ \\ ${ }^{1}$ HIV Out-Patient Clinic, Hospital for Infectious Diseases in Warsaw, Poland \\ ${ }^{2}$ Department of Adults' Infectious Diseases, Medical University of Warsaw, Poland
}

\begin{abstract}
Objectives: HIV-positive women are at increased risk of HPV infection and cervical cancer. European and national guidelines advise yearly screening for cervical cancer, however due to the lack of a central registration of HIV infected persons there is a gap in offering such care through general healthcare services in many countries, including Poland.

Material and methods: In response to the above limitations, integrated gynaecological care (IGC) was established at the HIV Out-Patient Clinic in Warsaw. We analysed data from January 2007 to May 2014. Logistic regression models were used to identify factors associated with not using IGC by patients.

Results: Two hundred and forty women were registered in the observation period:59.6\% infected through sexual contact, $18.7 \%$ through IDUs, $19.2 \%$ through unknown causes and $2.5 \%$ by other (two were vertically infected). The median follow-up time was 2.35 (IQR 0.9-4.5) years and $78.3 \%$ were on combination antiretroviral therapy (CART). In total 145 of the women (60.4\%) used IGC, from $72.1 \%$ of those registered in 2007 to $27.3 \%$ registered in 2014 . There were in total 1075 gynaecological visits and 254 cervical cytology tests performed. Seventy-five (51.7\%) women were tested for HPV infection. Factors decreasing the odds of not using IGC identified by multivariate regression models were being on CART (OR 0.25 [IQR: $0.10-0.59] ; p=0.003$ ) and longer time of observation (0.69 [0.58-0.83]; $p=0.0001$ ).

Conclusions: The utilisation of IGC was very high, but with a delay in commencing the IGC. Women on CART and with longer periods of follow-up had lower odds of not using IGC. A screening approach for women not yet on CART, or newly registered in the clinics, needs special attention.
\end{abstract}

Key words: HIV, cervical cancer, gynaecological care, integrated services, HPV

Ginekologia Polska 2018; 89, 2: 68-73

\section{INTRODUCTION}

Screening for human papilloma virus (HPV) infection is the most effective method of reducing both the incidence of and mortality from cervical cancer [1]. HIV-positive women are at increased risk of acquiring HPV and of the HPV infection and persistency of HPV infection, especially with high-risk HPV $[2,3]$. As a consequence, this group of women presents a five to six times higher risk of cervical cancer $[4,5]$. Therefore European and national guidelines recommend more frequent and age independent screening for cervical cancer among HIV positive women [6,7]. However, due to the lack of central registration of HIV infected persons, there is a gap in offering such screening through general healthcare services in many countries, including Poland. At the same time due to the stigma and discrimination HIV-positive women face and their fear of the disclosure of their HIV status, they do not inform their gynaecologist about their serostatus [8,9]. Some sub-groups of women, such as those who inject drugs or those living with two or more children may present a worse adherence to both HIV and gynaecological care [10, 11].

In Poland during the early period of the HIV epidemic, both stigmatisation of HIV persons and infection transmission 
through injecting drugs were common. In addition, there was a high rate of unplanned pregnancies among women with HIV and preventing vertical HIV transmission required strict follow-up [12]. Due to the above reasons and as a result of collaboration between gynaecologists and infectious disease specialists, the HIV Out-Patient Clinic in Warsaw introduced gynaecological care as part of its HIV services in the early 1990s.

Responding to the increasing interest in the effectiveness of integrating gynaecological care (IGC) in HIV clinics and the barriers to cervical cancer screening we have investigated the utilisation of gynaecological consultation and screening at the HIV Out-Patient Clinic in Warsaw.

\section{MATERIAL AND METHODS}

The IGC program was established in 1994 and consisted of free-of-charge gynaecological consultations and cervical cancer screening, made available without restrictions. Two trained gynaecologists were available twice weekly at the HIV clinic, which also provided a gynaecological cabinet equipped with colposcopy and diagnostic tests. Although the IGC was established in 1994, gynaecological visits have only been routinely registered in the electronic database since 2007. Therefore, we only analysed data from January 2007 until May 2014. The demographic characteristics and medical records were exported from the Polish Observational Cohort of HIV/AIDS Patients (POLCA) database. POLCA is a cohort of patients routinely observed at the HIV Out-Patient Clinic in Warsaw. Study methods are described elsewhere [13].

Use of the IGC was defined as a patient having at least one gynaecological consultation at the HIV clinic.

Cervical cytology was performed according to the standard methodology. HPV DNA detection and genotyping were performed using an HPV Genotypes 14 Real-TM Quant kit (Sacace, Italy). The following genotypes were able to be detected: 16, 18, 31, 33, 35, 39, 45, 51, 52, 56, 58, 59, 66 and 68. DNA extraction and amplification steps were done according to the manufacturer's protocol. PCR reactions were carried on CFX96 cycler (BioRad, USA). The results obtained were analyzed using software provided by the manufacturer.

In statistical analyses non-parametric tests were used for group comparison as appropriate. Univariate and multivariate logistic regression models were used to identify factors associated with not using IGC by women registered in the clinic. Factors identified as significant $(p<0.1)$ in univariate models were included in a multivariate model.

A confidence interval (Cl) of $95 \%$ was accepted. All analyses were performed using SAS version 9.3 (SAS Institute, Cary, NC, USA).

Ethical approval for the study had been obtained in accordance with Polish regulations; including obtaining written informed consent from each participant.

\section{RESULTS}

Two hundred and forty women were registered in the HIV clinic during the observation period. 143 (59.6\%) were infected through sexual contacts, 45 (18.7\%) through injected drug use and 6 (2.5\%) through other (two vertically infected) modes of transmission. Forty-six (19.2\%) women did not disclose the mode of transmission. The median follow-up time was 2.35 (Interquartile range, IQR: 0.9-4.5) years; the median age at registration was 30.1 (IQR:26.2-35.1) years; and the median baseline lymphocyte CD4+ count was 366 (179-545) cells/uL. One hundred and eighty-eight (78.3\%) women were on CART at the time of data analyses. One hundred and thirteen (48.1\%) women had CD4+ count below 350 cells/uL at baseline, thus meeting the criteria for late presenters. In terms of other co-infections 44 (18.3) women were anti-HCV positive; 38 (15.8\%) were anti-HBc total positive; 16 (6.7\%) had positive Venereal Disease Research Laboratory (VDRL) tests; but 22 (9.2\%) had indeterminate VDRL tests.

In total 145 women $(60.4 \%)$ used IGC, which ranged from $72.1 \%$ of those registered in 2007 to $27.3 \%$ of those registered in 2014 (Fig. 1); with 1079 gynaecological visits, 252 cervical cytology procedures and 94 HPV evaluations. The median number of gynaecological visits was 5 (IQR:2-11) with a minimum one and maximum of 34 visits per patient.

The median time from the first visit to the HIV clinic to the first gynaecological consultation was 0.4 years (IQR: 0.1-1.3). However, the median time from the first visit to the HIV clinic to first cytology result was 0.8 years $(0.15-1.95)$. In total 126 women, $85.5 \%$ of all using IGC, had at least one cytology, 65 (51.6\%) of them more than once. The median number of cervical cytology tests per patient was 1 (IQR:1-2). The number of cervical cytology tests performed per patient was higher in women on antiretroviral therapy, yet with no statistical difference (Tab. 1). Seventy-five women (51.7\%) were tested for HPV infection, but only 17 (22.7\%) more than once. The median number of HPV tests per patient was 1 (IQR:0-1).

In general, women not using IGC were less likely to declare a sexual mode of HIV transmission and more unlikely to disclose the mode of infection. A higher proportion of women from the IGC group had positive VDRL. Fifty-eight women (61\%) from the non-IGC group, compared with 130 women (89.7\%) from the IGC group had been on CART at the time of our data export (Tab. 2). At the same time, the IGC group had a higher median nadir lymphocyte CD4+ count and a lower proportion of them had baseline CD4+ counts below 350 cells/uL.

In univariate logistic regression models, women had significantly increased odds of not using the IGC if they had unknown (as compared to sexual) transmission modes 


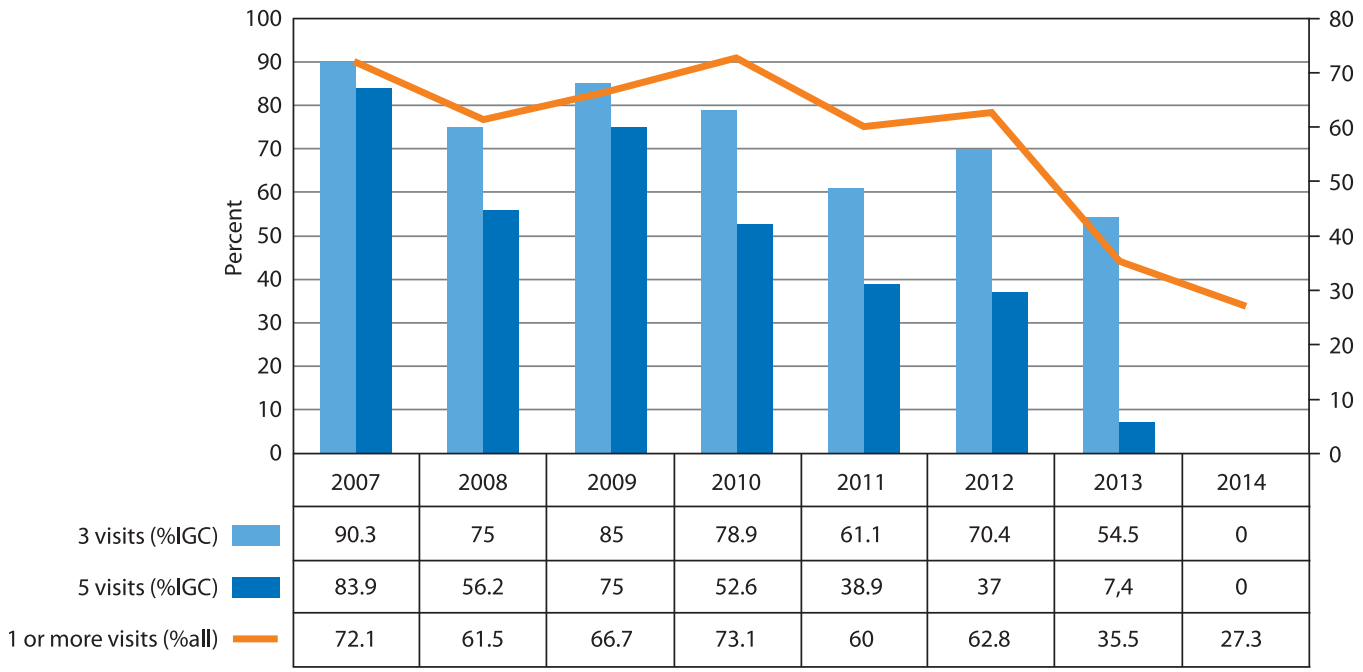

Figure 1. Gynaecological visits registered in integrated care stratified by calendar year

\begin{tabular}{|c|c|c|c|}
\hline \multicolumn{3}{|c|}{ Table 1. Number of cervical cytology tests performed per patient stratified by antiretroviral treatment status } \\
\hline $\begin{array}{c}\text { Number of tests } \\
\text { per patient }\end{array}$ & All patients & Patients not on cART & Patients on cART \\
\hline 1 & & Frequency (\%) & $52(46.0)$ \\
\hline 2 & $61(48.4)$ & $9(69.2)$ & $27(23.9)$ \\
\hline 3 & $30(23.8)$ & $3(23.1)$ & $19(16.8)$ \\
\hline 4 & $19(15.1)$ & $0(0)$ & $7(6.2)$ \\
\hline 5 & $7(5.5)$ & $0(0)$ & $6(5.3)$ \\
\hline 6 & $6(4.8)$ & $0(0)$ & $2(1.8)$ \\
\hline
\end{tabular}

(2.69 [1.36-5.32; $\mathrm{p}=0.04]$ ), unknown baseline (as compared to negative) VDRL (OR 4.79 [1.96-11.68; $\mathrm{p}=0.02]$ ) and higher nadir lymphocyte CD4+ counts (1.02 [1.01-1.04; $\mathrm{p}<0.001])$. At the same time, a woman's odds of not using the IGC decreased with each additional year in HIV care $(0.64$ [0.54-0.75; $p<0.0001])$, with a lymphocyte CD4+ count above 350 cells/ul, lower nadir lymphocyte CD4+ counts (0.58 [0.34-1.01; $p=0.05])$ and being on CART (0.18 [0.09$-0.35 ; \mathrm{p}<0.0001])$ (Tab. 2).

In multivariate logistic regression models, adjusted for all factors significant in the univariate models, being on CART (OR 0.25 [IQR: 0.10-0.59]; $p=0.003$ ) and having a longer time in HIV care (0.69 [0.58-0.83]; $p=0.0001)$ remained the only significant factors to decrease a woman's odds of not using IGC (Tab. 3).

\section{DISCUSSION}

The utilisation of IGC in Warsaw HIV Out-Patient Clinic was high, with almost two in three women attending at least one gynaecological consultation. However, a delay in entering gynaecological care was observed with one in four patients, who saw the gynaecologists more than a year after entering HIV care. In our multivariate analyses the odds for not using IGC were 31\% lower with each additional year of observation and $75 \%$ lower for women on CART. This suggests that women who are in care for longer periods might have a better understanding of the necessity of gynaecological supervision and be more willing to return to the HIV clinic for IGC. A recent Danish populational study showed comparable results, with CD4 count $>350$ cells $/ \mu \mathrm{L}$ and HIV RNA $<500$ copies/mL being predictors of attendance at the HIV cervical screening program [14]. In the Danish study only $2.6 \%$ of HIV positive women obtained the recommended two cervical cancer screenings in the first year from HIV diagnosis. In general, throughout the study period, the authors analysed different time intervals, with the range of HIV-positive women who followed the HIV cervical screening guidelines being from $29 \%$ to $46 \%$. Compared with the above, a multicentre Catalan study revealed inadequate rates of cervical cancer screening with only $50 \%$ of HIV positive women reporting that they had annual screening [15]. It is worth mentioning that in a prospective study of HPV infection among HIV positive women from European countries with a study population of over 


\begin{tabular}{|c|c|c|c|c|}
\hline Parameter & $\begin{array}{c}\text { Total } \\
N=240\end{array}$ & $\begin{array}{l}\text { Women using IGC } \\
\qquad N=145\end{array}$ & $\begin{array}{l}\text { Women not using } \\
\qquad \begin{array}{c}\text { IGC } \\
N=95\end{array}\end{array}$ & $P$ value \\
\hline & \multicolumn{3}{|c|}{$\mathbf{N}(\%)$} & \\
\hline \multicolumn{4}{|l|}{ Mode of HIV transmission } & \multirow{5}{*}{0.02} \\
\hline Sexual contacts & $143(59.6)$ & $94(64.8)$ & $49(51.6)$ & \\
\hline IDU & $45(18.7)$ & 27 (18.6) & $18(18.9)$ & \\
\hline Other & $6(2.5)$ & $4(2.8)$ & $2(2.1)$ & \\
\hline Unknown & $46(19.2)$ & $20(13.8)$ & $26(27.4)$ & \\
\hline Anty-HCV positive* & $44(18.3)$ & $26(17.9)$ & $18(18.9)$ & 0.19 \\
\hline Anty-HBc total positive* & $38(15.8)$ & $21(14.5)$ & $17(17.9)$ & 0.11 \\
\hline VDRL positive* & $16(6.7)$ & $8(5.5)$ & $8(8.4)$ & $<0.01$ \\
\hline On CART & $188(78.3)$ & $130(89.7)$ & $58(61.0)$ & $<0.0001$ \\
\hline \multirow[t]{2}{*}{ CD4 count $<350$ cells $/ \mu \mathrm{L}$ on baseline } & $113(48.1)$ & $77(53.1)$ & $36(40.0)$ & 0.06 \\
\hline & \multicolumn{3}{|c|}{ Median (IQR) } & \\
\hline Age at registration in years* & $30.1(26.2-35.1)$ & $29.1(26.2-33.7)$ & $31.4(26.2-35.7)$ & 0.12 \\
\hline Baseline lymphocyte CD4+ count cells/ $\mu L^{*}$ & $366(179-545)$ & $336(163-539)$ & $384(222-549)$ & 0.24 \\
\hline Nadir CD4+ count cells/ $\mu \mathrm{L}$ (nadir) & $260(142-416)$ & $221(114-321)$ & $344(207-462)$ & $<0.001$ \\
\hline HIV RNA copies/mL* & $5279(280-514)$ & $7311(468-56500)$ & $3100(56-32889)$ & 0.07 \\
\hline Years of follow-up & $2.35(0.9-4.5)$ & $3.2(1.6-5.4)$ & $1.0(0.2-2.8)$ & $<0.0001$ \\
\hline
\end{tabular}

HIV — human immunodeficiency virus; VDRL — Veneral Disease Research Laboratory

\begin{tabular}{|c|c|c|c|c|c|c|}
\hline \multirow[t]{2}{*}{ Parameter } & \multicolumn{3}{|c|}{ Univariate analyses } & \multicolumn{3}{|c|}{ Multivariate analysis } \\
\hline & OR & $95 \% \mathrm{Cl}$ & P value & OR & $95 \% \mathrm{Cl}$ & P value \\
\hline \multicolumn{7}{|l|}{ Mode of infection } \\
\hline Sexual contacts & - & - & - & - & - & - \\
\hline IDU & 1.38 & $0.69-2.76$ & 0.96 & 1.12 & $0.51-2.49$ & 0.90 \\
\hline Other & 1.03 & $0.18-5.85$ & 0.65 & 1.10 & $0.14-8.37$ & 0.92 \\
\hline Unknown & 2.69 & $1.36-5.32$ & 0.04 & 1.55 & $0.69-3.52$ & 0.47 \\
\hline VDRL negative & - & - & - & - & - & - \\
\hline VDRL positive & 1.86 & $0.64-5.39$ & 0.78 & 2.65 & $0.80-8.80$ & 0.46 \\
\hline VDRL uncertain & 2.13 & $0.87-5.21$ & 0.96 & 2.23 & $0.80-6.30$ & 0.67 \\
\hline VDRL unknown & 4.79 & $1.96-11.68$ & 0.02 & 2.06 & $0.73-5.81$ & 0.82 \\
\hline On CART & 0.18 & $0.09-0.35$ & $<0.0001$ & 0.25 & $0.10-0.59$ & 0.003 \\
\hline $\begin{array}{l}\text { Presentation at } \\
\mathrm{CD} 4 \text { count }<350 \text { cells } / \mu \mathrm{L}\end{array}$ & 0.58 & $0.34-1.01$ & 0.05 & 0.30 & $0.10-0.91$ & 0.91 \\
\hline Age at registration in years & 1.02 & $0.99-1.05$ & 0.13 & - & - & - \\
\hline $\begin{array}{l}\text { Baseline CD4+ count (cells } / \mu \mathrm{L} \text { ) } \\
\text { (per } 1 \text { cell increase) }\end{array}$ & 1.00 & $0.99-1.01$ & 0.93 & - & - & - \\
\hline $\begin{array}{l}\text { Nadir CD4+ (per } 10 \text { cells } \\
\text { increase) }\end{array}$ & 1.02 & $1.01-1.04$ & $<0.001$ & 1.00 & $0.99-1.00$ & 0.95 \\
\hline $\begin{array}{l}\text { Years in care ( } 1 \text { per year } \\
\text { increase) }\end{array}$ & 0.64 & $0.54-0.75$ & $<0.0001$ & 0.69 & $0.58-0.83$ & 0.0001 \\
\hline
\end{tabular}

IDU — injected drug users; $\mathrm{Cl}$ - confidence interval; $\mathrm{OR}$ - odds ratio 
1100 women, only $55.5 \%$ provided a second sample after 6 or more months [3].

In our study of women receiving routine care, over half the women had two or more cytological tests performed, which is still an unsatisfactory result. Especially worrisome is the much lower repeatability of HPV screening, as HPV-based screening has proved to provide 60 to $70 \%$ greater protection against invasive cervical cancer than cytology [1].

As identified by Konopnicky et al., women with lower lymphocyte CD4+ cell counts and who are not yet on CART are at higher risk of developing cervical dysplasia. At the same time it has been shown that being on CART with immune reconstitution is associated with reducing the risk of persistent cervical high-risk human papillomavirus infection [16]. It is therefore worrying that even in the presence of gynaecological services at the HIV clinic these women who are not yet on CART are less likely to receive consultations. A special focus should be put on patients entering care to make sure they understand the importance of gynaecological screening and of following the physician's recommendations [17].

Interestingly, according to the baseline characteristics, women not using IGC were less likely to declare sexual modes of HIV transmission and more likely to declare unknown modes of transmission. At the same time, they had higher rates of positive VDRL. This could reflect their self-stigmatisation and denial of risk behaviours; and this factor underlines the need for psychological and social peer support [18]. For this group of women, alternative methods, such as self-collected samples, should be considered. A recent meta-analysis by Arbyn et al. in 2014 shows a growing body of evidence to suggest that self-collected samples can be an alternative strategy to reach women who are not participating in routine cervical cancer screening programmes [19].

It is often presumed that cervical cancer screening coverage is satisfactory in Europe, with the consequent presumption that special attention is not needed for the screening of HIV women. However, data coming from observational studies in Europe, although scarce, shows that barriers to cervical cancer screening still exist, from both the patient's and the health system's perspectives $[14,15,20]$. It is important to note that according to a recently published EuroSIDA study of a pan-European longitudinal observational cohort, cancer screening has a low coverage in both Eastern and non-Eastern European countries [21].

Screening approaches for HIV positive women in Poland, especially for those not yet on CART or those newly registered in the HIV clinics, needs special attention. Integrating gynaecological services into HIV care is suggested as a way of improving coverage for cervical cancer screening; however, barriers to gynaecological consultations exist even in the presence of such integration.

\section{Acknowledgments}

This study received a research grant from the Research Development Foundation of the Hospital for Infectious Diseases in Warsaw. The Foundation had no influence on the study design, analyses or preparing the manuscript. None of the authors declared conflict of interests.

\section{REFERENCES}

1. Ronco G, Dillner J, Elfström KM, et al. International HPV screening working group. Efficacy of HPV-based screening for prevention of invasive cervical cancer: follow-up of four European randomised controlled trials. Lancet. 2014; 383(9916): 524-532, doi: 10.1016/S01406736(13)62218-7, indexed in Pubmed: 24192252.

2. Konopnicki D, Manigart Y, Gilles $C$, et al. High-risk human papillomavirus genotypes distribution in a cohort of HIV-positive women living in Europe: epidemiological implication for vaccination against human papillomavirus. AIDS. 2016; 30(3): 425-433, doi: 10.1097/QAD.0000000000000929, indexed in Pubmed: 26765936.

3. Heard I, Cubie HA, Mesher D, et al. MACH-1 Study Group. Characteristics of HPV infection over time in European women who are HIV-1 positive. BJOG. 2013; 120(1): 41-49, doi: 10.1111/1471-0528.12015, indexed in Pubmed: 23121095.

4. Frisch M, Biggar RJ, Goedert JJ. Human papillomavirus-associated cancers in patients with human immunodeficiency virus infection and acquired immunodeficiency syndrome. J Natl Cancer Inst. 2000; 92(18): 1500-1510, doi: 10.1093/jnci/92.18.1500, indexed in Pubmed: 10995805.

5. Clifford GM, Franceschi S, Keiser O, et al. Swiss HIV Cohort Study. Immunodeficiency and the risk of cervical intraepithelial neoplasia $2 / 3$ and cervical cancer: A nested case-control study in the Swiss HIV cohort study. Int J Cancer. 2016; 138(7): 1732-1740, doi: 10.1002/ijc.29913, indexed in Pubmed: 26537763.

6. PTN AIDS. Zasady opieki nad osobami zakażonymi HIV. http://www. ptnaids.pl/pliki/zalecenia_2016_uzupelnione.pdf (2016).

7. European AIDS Clinical Society Guidelnes. Version 8.1. October 2016. http://www.eacsociety.org/guidelines/eacs-guidelines/eacs-guidelines. html (Accessed 22 November 2016.).

8. Nachega JB, Morroni C, Zuniga JM, et al. HIV-related stigma, isolation, discrimination, and serostatus disclosure: a global survey of 2035 HIV-infected adults. J Int Assoc Physicians AIDS Care (Chic). 2012; 11(3): 172 -178, doi: 10.1177/1545109712436723, indexed in Pubmed: 22431893.

9. The People Living with HIV Stigma Index (STIGMA Index) project. HIV-related stigma: late testing, late treatment. A cross analysis of findings from the people living with HIV Stigma Index in Estonia, Moldova, Poland, Turkey, and Ukraine. 2010. http://www.gnpplus. net/images/stories/Rights_and_stigma/2011_HIVStigma_Report_ EN.pdf (23 Nov 2013).

10. Reference Group to the United Nations on HIV and Injecting Drug Use. Women who inject drugs: A review of their risks, experiences and needs. http://hivhealthclearinghouse.unesco.org/library/documents/women-who-inject-drugs-review-their-risks-experiences-andneeds (Accessed on: 13 Dec 2016).

11. Merenstein DJ, Schneider MF, Cox $C_{1}$ et al. Association between living with children and adherence to highly active antiretroviral therapy in the Women's Interagency HIV Study. Pediatrics. 2008; 121(4): e787-e793, doi: 10.1542/peds.2007-1586, indexed in Pubmed: 18381507.

12. Niemiec KT, Horban A, Chazan B, et al. [Antiretroviral therapy in pregnant women with HIV]. Ginekol Pol. 1998; 69(11): 820-826, indexed in Pubmed: 10337075.

13. Kowalska JD, Kubicka J, Siwak E, et al. Polish Observational Cohort of HIV/AIDS Patients (POLCA) Study Group. Factors associated with the first antiretroviral therapy modification in older HIV-1 positive patients. AIDS Res Ther. 2016; 13: 2, doi: 10.1186/s12981-015-0084-5, indexed in Pubmed: 26744599.

14. Thorsteinsson $K$, Ladelund S, Jensen-Fangel S, et al. Adherence to the cervical cancer screening program in women living with HIV in Denmark: comparison with the general population. BMC Infect Dis. 2014; 14: 256, doi: 10.1186/1471-2334-14-256, indexed in Pubmed: 24885577.

15. Stuardo V, Agustí C, Godinez JM, et al. Human papillomavirus infection in HIV-1 infected women in Catalonia (Spain): implications for prevention of cervical cancer. PLoS One. 2012; 7(10): e47755, doi: 10.1371/journal. pone.0047755, indexed in Pubmed: 23118894. 
16. Konopnicki D, Manigart $Y$, Gilles $C$, et al. Sustained viral suppression and higher CD4+ T-cell count reduces the risk of persistent cervical high-risk human papillomavirus infection in HIV-positive women. J Infect Dis. 2013; 207(11): 1723-1729, doi: 10.1093/infdis/jit090, indexed in Pubmed: 23463709.

17. Giorgi Rossi P, Baldacchini F, Ronco G. The Possible Effects on Socio-Economic Inequalities of Introducing HPV Testing as Primary Test in Cervical Cancer Screening Programs. Front Oncol. 2014; 4: 20, doi: 10.3389/fonc.2014.00020, indexed in Pubmed: 24575388.

18. Smith LW, Khurshed F, van Niekerk DJ, et al. Women's intentions to self-collect samples for human papillomavirus testing in an organized cervical cancer screening program. BMC Public Health. 2014; 14: 1060, doi: 10.1186/1471-2458-14-1060, indexed in Pubmed: 25303975.
19. Arbyn M, Verdoodt F, Snijders PJF, et al. Accuracy of human papillomavirus testing on self-collected versus clinician-collected samples: a meta-analysis. Lancet Oncol. 2014; 15(2): 172-183, doi: 10.1016/S14702045(13)70570-9, indexed in Pubmed: 24433684

20. Ursu RG, Onofriescu M, Luca A, et al. The Need for Cervical Cancer Control in HIV-Positive and HIV-Negative Women from Romania by Primary Prevention and by Early Detection Using Clinically Validated HPV/DNA Tests. PLoS One. 2015; 10(7): e0132271, doi: 10.1371/journal. pone.0132271, indexed in Pubmed: 26186361.

21. Laut KG, Mocroft A, Lazarus J, et al. Eurosida in Eurocoord. Regional differences in self-reported HIV care and management in the EuroSIDA study. J Int AIDS Soc. 2014; 17(4 Suppl 3): 19504, doi: doi: 10.7448/ias.17.4.19504, indexed in Pubmed: 25394013. 